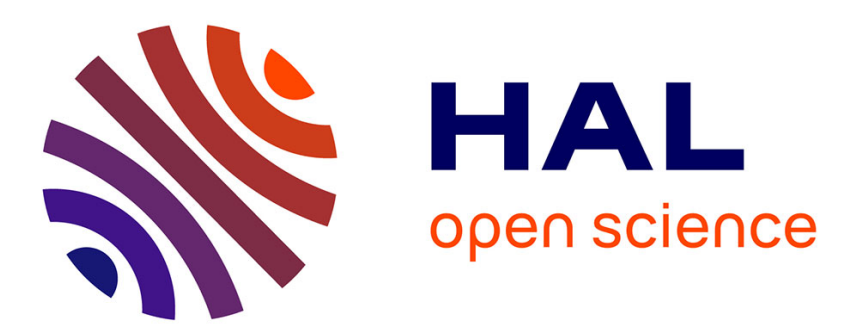

\title{
Alkylphenol oxidation with a laccase from a white-rot fungus: Effects of culture induction and of ABTS used as a mediator
}

Anne Marie Farnet da Silva, A.C. Chevremont, G. Gil, S. Gastaldi, Elisée Ferré

\section{To cite this version:}

Anne Marie Farnet da Silva, A.C. Chevremont, G. Gil, S. Gastaldi, Elisée Ferré. Alkylphenol oxidation with a laccase from a white-rot fungus: Effects of culture induction and of ABTS used as a mediator. Chemosphere, 2011, 82 (2), pp.284-289. 10.1016/j.chemosphere.2010.10.001 . hal-02069509

\section{HAL Id: hal-02069509 https://hal.science/hal-02069509}

Submitted on 15 Mar 2019

HAL is a multi-disciplinary open access archive for the deposit and dissemination of scientific research documents, whether they are published or not. The documents may come from teaching and research institutions in France or abroad, or from public or private research centers.
L'archive ouverte pluridisciplinaire HAL, est destinée au dépôt et à la diffusion de documents scientifiques de niveau recherche, publiés ou non, émanant des établissements d'enseignement et de recherche français ou étrangers, des laboratoires publics ou privés. 


\title{
Alkylphenol oxidation with a laccase from a white-rot fungus: Effects of culture induction and of ABTS used as a mediator
}

\author{
A.M. Farnet ${ }^{\mathrm{a}, *}$, A.C. Chevremont ${ }^{\mathrm{a}}$, G. Gil $^{\mathrm{b}}, \mathrm{S}$. Gastaldi ${ }^{\mathrm{c}}$, E. Ferre $^{\mathrm{a}}$ \\ ${ }^{a}$ Equipe Ecologie Microbienne et Biotechnologies, UMR CNRS IRD 6116, Institut Méditerranéen d'Ecologie et de Paléoécologie, Faculté des Sciences et Techniques de St \\ Jérôme, Université Paul Cézanne, 13397 Marseille, France \\ ${ }^{\mathrm{b}}$ Equipe Chirosciences, UMR CNRS 6263, Université Paul Cézanne, Faculté des Sciences et Techniques de St. Jérôme, 13397 Marseille, Cedex 20, France \\ ${ }^{\mathrm{c}}$ Equipe Chimie Moléculaire Organique, LCP UMR 6264, Boite 562, Université Paul Cézanne, Aix-Marseille III, Faculté des Sciences St Jérôme, Avenue Escadrille \\ Normandie-Niemen, 13397 Marseille, Cedex 20, France
}

Keywords:

Endocrine disruptive chemicals

Laccase

Mediators

Polymerisation

\begin{abstract}
A B S T R A C T
We investigated the potential of the laccase from the white-rot fungus Marasmius quercophilus to transform certain alkylphenols ( $p$-nonylphenol, $p$-octylphenol and $p$-t-octylphenol). We tested the reactivity of this enzyme under different conditions: in liquid cultures and using the partially purified laccase with and without 2,2'-azino-bis-3-ehtylbenzothiazoline-6-sulfonicacid (ABTS) as a mediator. The percentage of $p$ - $t$-octylphenol disappearance in liquid cultures was $69.0 \pm 1.5 \%$ and $81 \pm 5 \%$ after a 8 - $d$ or 15 - $d$ incubation, respectively, with $p$-nonylphenol, these percentages were $62 \pm 4 \%$ and $91 \pm 6 \%$ and with $p$-octylphenol $37 \pm 3 \%$ and $65 \pm 1 \%$ after a 15 - $d$ and a 21 -d incubations, respectively. Induced pre-cultures were also used to inoculate the liquid cultures to enhance $p$-octylphenol transformation: the percentages of disappearance were $91.0 \pm 0.5 \%$ and $97 \pm 1 \%$ after a 8 - $\mathrm{d}$ and a 15 -d incubation, respectively. Mass spectrometry analysis showed that the products of oxidation of $p$-octylphenol were dimers with a mass of $411 \mathrm{~m} / z$. Furthermore, we identified a purple compound $(\mathrm{m} / \mathrm{z} 476)$ formed when ABTS was added to the reaction medium with the purified laccase. This result confirms that, in complex environments such as soils or litters where many molecules can interact with the enzyme substrate or the product of oxidation, laccase activities and those of other phenoloxidases should not be measured with ABTS.
\end{abstract}

\section{Introduction}

Many natural and synthetic chemical compounds exhibit estrogenic activities. These are known as endocrine disrupting compounds, EDCs (Mc Lachland, 1985) and include bisphenol A (2,2-bis(4-hydroxy-phenol)propane), various alkylphenols or triclosan (5-chloro-2(2,4-dichloro-phenoxy)phenol). These compounds have significant ecotoxicological effects in aquatic environments contaminated with wastewaters in intensively urbanised areas (Svenson et al., 2003; Peck et al., 2004; Schiliro et al., 2003; Nagarnaik et al., 2010). For instance, these molecules may affect sex ratio changes or reduce fecundity of fish (Nagler et al., 2001; Chowen and Nagler, 2004). Alkylphenols, such as $p$-nonylphenol and p-octylphenol, are environmentally persistent molecules with estrogenic activities: they are produced via the microbial transformation of alkylphenol polyethoxylates in sewage treatment plants (Tollefsen et al., 2008). Lignin-degrading enzymes i.e. phenoloxidases (laccases, Mn-peroxidases or lignin-peroxidases) have been extensively used to

\footnotetext{
* Corresponding author. Tel./fax: +3349128 8190 .

E-mail address: a-m.farnet@univ-cezanne.fr (A.M. Farnet).
}

transform many aromatic pollutants such as PAHs (polycyclic aromatic hydrocarbons), chlorophenols or EDCs (Tanaka et al., 2003; Saito et al., 2004; Torres-Duarte et al., 2009; Uhnakova et al., 2009). These enzymes, mainly produced by white-rot fungi, are involved in the transformation of natural aromatic compounds. Moreover, their non-specific oxidation makes the transformation of pollutants with similar aromatic structure possible. Thus these enzymes, which have a broad substrate specificity, have been extensively tested for biotechnological applications (Ghosh et al., 2008).

Marasmius quercophilus, a white-rot fungus which was isolated from Mediterranean ecosystems such as Quercus ilex or Quercus suber litters, mainly produces laccases. Recent studies have demonstrated their potential in transforming aromatic pollutants such as PAHs or chlorophenols (Farnet et al., 2004, 2008). For instance, these laccases were able to oxidise anthracene to anthaquinone and to remove chloride from chlorophenols. Thus the laccases produced by this fungus seem to exhibit an oxidative potential which can be used towards various aromatic pollutants. This potential can be of major importance in litters colonised by this fungus since it can be involved in detoxification of natural environments. Furthermore these enzymes can easily be used in biotechnological 
applications since they can be produced in high amounts, no cofactors are needed for the reaction they catalyse and they are very stable at quite high temperatures ( $80 \%$ of remaining activity after $48 \mathrm{~h}$ at $40^{\circ} \mathrm{C}$, Farnet et al., 2004).

Here, we examine the potential modification of various alkylphenols using the laccase of $M$. quercophilus in liquid cultures or using the purified laccase with or without a common laccase mediator, ABTS. We partially describe the mechanisms of oxidation of laccase with or without ABTS via the products of $p$-toctylphenol oxidation which were determined using mass spectrometry.

\section{Materials and methods}

\subsection{Isolation of the strain}

M. quercophilus strain 19 was isolated from an area of the site of La Gardiole de Rians, Var, France $\left(10000 \mathrm{~m}^{2}\right)$ using the rhizomorphic form of the fungus. First, a fungal cap culture was made on a malt-agar medium, $20 \mathrm{~g} \mathrm{~L}^{-1}$ (Bio Mérieux, Marcy l'Etoile, France) and chloramphenicol, $50 \mathrm{mg} \mathrm{L}^{-1}$ (Sigma). Second, the pure mycelial culture obtained was used to inoculate an agar medium (whole wheat flour, $20 \mathrm{~g} \mathrm{~L}^{-1}$ ) which favours rhizomorph production. Then one rhizomorph was used to inoculate a malt-agar plate to obtain a pure dicaryotic culture.

\subsection{Partial purification of the laccase of M. quercophilus}

The partial purification was performed as described by Farnet et al. (2004). Pre-cultures were realised in $200 \mathrm{~mL}$ Erlenmeyer flasks containing $50 \mathrm{~mL}$ of malt extract liquid medium, $20 \mathrm{~g} \mathrm{~L}^{-1}$ (MEL) in static conditions at $28^{\circ} \mathrm{C}$. They were inoculated with a plug of agar cultures $\left(15 \mathrm{~g} \mathrm{~L}^{-1}\right)$ with malt extract $\left(20 \mathrm{~g} \mathrm{~L}^{-1}\right)$. These liquid pre-cultures were used to inoculate two $3000 \mathrm{~mL}$ Erlenmeyer flasks with $800 \mathrm{~mL}$ of malt extract medium $\left(20 \mathrm{~g} \mathrm{~L}^{-1}\right)$, Tween $80,0.05 \%, \mathrm{CuSO}_{4}, 5 \mathrm{mg} \mathrm{L}^{-1}$. They were incubated at $25^{\circ} \mathrm{C}$ for $12 \mathrm{~d}$ under axial shaking. Enzyme activity was measured by monitoring the oxidation of syringaldazine [N,N'-bis-(3,5-dimethoxy-4-hydroxybenzylidene)hydrazine] to its quinone $\left(\varepsilon^{\mathrm{M}}: 6.5 \times 10^{4} \mathrm{M}^{-1} \mathrm{~cm}^{-1}\right.$ ) at $525 \mathrm{~nm}$ (Harkin et al., 1974) on a spectrophotometer Kontron Uvikon 860 (Serlabo Technologies, Entraigues, France). The assay contained $100 \mu \mathrm{L}$ of the culture medium, $2.5 \mathrm{~mL}$ of acetate buffer $0.1 \mathrm{M}, \mathrm{pH} 4.5$ and $10 \mu \mathrm{L}$ of syringaldazine $0.6 \%(\mathrm{w} / \mathrm{v})$, diluted in methanol. The blank consisted of $100 \mu \mathrm{L}$ of the culture medium and $2.5 \mathrm{~mL}$ of the same acetate buffer. Peroxydase activities were also measured using $\mathrm{H}_{2} \mathrm{O}_{2}$ and $\mathrm{MnSO}_{4}$. When laccase activity was detected, cultures were filtered on a glass microfibre filter $\mathrm{GF} / \mathrm{D}, 2.7 \mu \mathrm{m}$ (Whatman, England). Then, the filtered culture medium was concentrated in dialysis tubes rated at $12 \mathrm{kDa}$ (32 mm diameter, Poly Labo) using polyethyleneglycol. The samples from the different tubes were pooled using acetate buffer $10 \mathrm{mM}, \mathrm{pH} 4.5$ in a final volume of $15 \mathrm{~mL}$. The concentrated filtered medium was loaded on an ion-exchange Mono $\mathrm{Q}$ column in fast performance liquid chromatography (FPLC) equilibrated with phosphate buffer $0.1 \mathrm{M} \mathrm{pH}$ 6.0. Laccase was eluted with a step gradient $(0.2 \mathrm{M}, 0.4 \mathrm{M}, 2 \mathrm{M} \mathrm{NaCl})$ for $30 \mathrm{~min}$ at a flow rate of $1 \mathrm{~mL} \mathrm{~min}^{-1}$ (Farnet et al., 2004). Laccase activity was measured as described above to detect fractions containing laccase. Laccase purity was checked on a polyacrylamide gel electrophoresis (PAGE) carried out according to Laemmli (1970) using 4\% stacking gel and $7.5 \%$ separating gel at $220 \mathrm{~V}$ with the Mini-Protean II electrophoresis cell (Bio-rad) and protein was stained using the Coomassie Blue standard method.

\subsection{Cultures of M. quercophilus with alkylphenols}

Cultures, previously inoculated with $10 \mathrm{~mL}$ of preculture of strain 19 , were performed for 8 or $15 \mathrm{~d}$ on a rotary shaker (200 rpm) at $25{ }^{\circ} \mathrm{C}$ in $1 \mathrm{~L}$-Erlenmeyer flasks with $200 \mathrm{~mL}$ of MEL including $50 \mathrm{mg}$ of $p$-octylphenol, 4-(1,1,3,3-tetramethylbutyl)phenol, ( $p$-t-octylphenol) or $p$-nonylphenol. From day four, laccase activities were measured every day with syringaldazine as the substrate as described above. Cultures with $800 \mathrm{~mL}$ of MEL and $200 \mathrm{mg}$ of alkylphenols were also performed. Different control cultures without mycelium were performed: control cultures after autoclaving and control cultures incubated in the same conditions and for both incubation periods assess alkylphenol evaporation during sterilisation or incubation time, respectively. Each experiment was performed in three replicates. Induction experiments were also performed using pre-cultures with $200 \mathrm{~mL}$ of MEL with p-octylphenol $\left(50 \mathrm{mg} \mathrm{L}^{-1}\right)$. These pre-cultures were incubated for $8 \mathrm{~d}$ at $25^{\circ} \mathrm{C}$ and then were used to inoculate cultures with $200 \mathrm{~mL}$ of MEL with $p$-octylphenol $\left(250 \mathrm{mg} \mathrm{L}^{-1}\right)$.

For all these experiments, cultures were filtered and both the mycelium and the supernatant were extracted three times with $200 \mathrm{~mL}$ of dichloromethane. The solvent was then evaporated and the solid extract solubilised in $1 \mathrm{~mL}$ of ethanol. Thirty microliter of dilution $10^{-3}$ were injected in the HPLC system. Alkylphenol transformation was calculated as percentages using calibration curve described previously.

\subsection{Sodium dodecyl sulfate (SDS) - polyacrylamide gel electrophoresis (PAGE)}

For all the cultures with alkylphenols, SDS-PAGE were performed in order to check whether any laccase isoforms were induced. Electrophoresis was carried out according to Laemmli (1970) using 4\% stacking gel and $12 \%$ separating gel at $220 \mathrm{~V}$ with the Mini-Protean II electrophoresis cell (Bio-Rad). For laccase activity staining, $p$-phenylenediamine $(0.1 \%)$ was used as the substrate in acetate buffer $0.1 \mathrm{M}, \mathrm{pH} 4$.

\subsection{Statistical analysis}

The non-parametric U-test of Mann-Whitney was used to separate significantly different means $(P<0.05)$ of remaining alkylphenols under the different experimental conditions. These analyses were performed using SPSS 11.0 statistical software (SPSS Inc., Chicago, IL).

\subsection{Analysis of alkylphenol transformation with high performance liquid chromatography (HPLC)}

HPLC system was equipped with a C18 Reverse Phase column (Merck, $4.6 \times 250 \mathrm{~mm}$ ) in the following gradient system: solvent A, (water/trifluoro acetic acid 0.1\%)/acetonitrile 90/10 v/v, solvent $\mathrm{B}$ (water/trifluoro acetic acid $0.1 \%$ )/acetonitrile $95 / 5 \mathrm{v} / \mathrm{v}$, gradient $=5-15 \mathrm{~min}$, A $100 \%$ to B $100 \% ; 15-25 \mathrm{~min}$ B $100 \%$ (flow rate $1 \mathrm{~mL} \mathrm{~min}^{-1}$ ). The alkylphenols tested were transformed realised using the laccase extract. The reaction mixture $(5 \mathrm{~mL})$ contained ABTS $1 \mathrm{mM}$, alkylphenol $250 \mathrm{mg} \mathrm{L}^{-1}$ and $5 \mathrm{U}$ of laccase in acetate buffer $0.1 \mathrm{M} \mathrm{pH} 4.5$ and $10 \%$ ethanol. The reaction mixtures were incubated at $30^{\circ} \mathrm{C}$ for $6 \mathrm{~h}$ in the dark. An extraction with $5 \mathrm{~mL}$ of dichloromethane was performed for each reaction mixture prior to injection. The organic phase was evaporated and the products of extraction were dissolved in $1 \mathrm{~mL}$ of acetonitrile (30 $\mu \mathrm{L}$ injected). The alkylphenols used were: $p$-octylphenol, $p$-t-octylphenol and $p$-nonylphenol. All alkylphenols were purchased from Sigma. The same reactions were performed without mediators. Controls were also realised using only ABTS with laccase and using 
ABTS with the alkylphenol but without laccase. All these controls were incubated at $30^{\circ} \mathrm{C}$ for $6 \mathrm{~h}$. p-Hydroxybenzoic acid was used as reference in each injection. A calibration curve was also performed for alkylphenol concentrations ranging from 50 to $400 \mu \mathrm{M}$. Results were expressed as percentages of alkylphenol disappearance.

\subsection{MS analysis}

Mass spectrometry was performed with a Spectrophotometer QStar Elite (Applied Biosystems SCIEX) equipped with an electrospray atmospheric pressure ionisation (ESI) source in the positive ion monitoring mode. The ESI conditions were set as follows: electrospray voltage (ESV), $5500 \mathrm{~V}$, orifice voltage (OR), $70 \mathrm{~V}$, gas nebulisation pressure, $20 \mathrm{psi}$ (138 kPa), collision energy (CE), $15 \mathrm{eV}$.

\section{Results and discussion}

M. quercophilus is a white-rot basidiomycete whose laccases have been involved in the transformation of various organic pollutants, mainly chlorophenols and PAH such as anthracene (Farnet et al., 2004, 2008). Here, we investigate the potential of these enzymes to transform different alkylphenols using both liquid cultures and a partially purified isoform of laccase.

Different culture conditions were used to test alkylphenol transformation in liquid cultures with M. quercophilus. Both liquid medium and mycelium were extracted to check whether any adsorption of alkylphenols occurred on the hyphae. Liquid cultures of $200 \mathrm{~mL}$ containing alkylphenols at $200 \mathrm{mg} \mathrm{L}^{-1}$ were performed. Under these conditions, the percentages of transformation were particularly high after 15 -d incubation with $p$-t-octylphenol and $p$-nonylphenol ( $81 \pm 5 \%$ and $91 \pm 6 \%$ respectively), while the weaker percentage was obtained with $p$-octylphenol $(37.0 \pm 3.5 \%)$. The transformation of these molecules was also tested in cultures of $800 \mathrm{~mL}$ with $200 \mathrm{mg} \mathrm{L}^{-1}$ of alkylphenols. After a 21-d incubation, the percentages of disappearance of $p$-octylphenol, $p$-nonylphenol and $p$-t-octylphenol were $100 \%, 92 \%$ and $90 \%$, respectively (data not shown). Thus, the partial solubility of alkylphenols in water did not affect their transformation by the M. quercophilus laccase. No solvents were added in the culture medium since their toxicity towards the fungus may have altered its growth. It is also noteworthy that the only phenoloxidase activity detectable in the culture medium was that of laccase, which shows that neither Mn-peroxidase nor lignin-peroxidase were responsible for this transformation.

In order to enhance $p$-octylphenol transformation, laccase induction via pre-cultures with $p$-octylphenol $\left(50 \mathrm{mg} \mathrm{L}^{-1}\right)$ were performed. These pre-cultures were then used to inoculate the cultures to test $p$-octylphenol transformation $\left(250 \mathrm{mg} \mathrm{L}^{-1}\right)$. This time, the percentages of disappearance were $91.0 \pm 0.5 \%$ and $97 \pm 1 \%$ after a 8 -d and a 15-d incubation, respectively (Table 1). Thus inducing pre-cultures significantly enhances the percentage of $p$ -

Table 1

Percentages of transformation of alkylphenols in cultures of Marasmius quercophilus after different incubation times.

\begin{tabular}{rlll}
\hline & \multicolumn{2}{l}{$\%$ of Transformation } \\
\cline { 2 - 4 } Incubation time $(\mathrm{d})$ & $p$-Octylphenol & $\begin{array}{l}p \text {-t- } \\
\text { Octylphenol }\end{array}$ & $\begin{array}{l}p \text { - } \\
\text { Nonylphenol }\end{array}$ \\
\hline 8 & $15.0 \pm 1.5\left(57 \pm 1^{\mathrm{a}}\right)$ & $69.0 \pm 1.5$ & $62 \pm 4$ \\
15 & $37.0 \pm 3.5\left(97 \pm 1^{\mathrm{a}}\right)$ & $81 \pm 5$ & $91 \pm 6$ \\
21 & $65 \pm 0.8$ & $90 \pm 2$ & $92 \pm 1$ \\
\hline
\end{tabular}

a $\%$ of transformation of $p$-octylphenol obtained with cultures inoculated with induced pre-cultures. octylphenol transformation. Laccase induction has been reported under different conditions such as antagonisms between microorganisms (Velazquez-Cedeno et al., 2007) or when cultures are complemented with aromatic compounds (Farnet et al., 1999). Induction can either lead to the production of new isoforms of enzymes or enhance the production of the constitutive isoform with an increase in laccase activity as a result. Here, laccase was produced for a longer time in cultures inoculated with pre-cultures induced with p-octylphenol (Fig. 1a). Laccase activity indeed increased after 11- and 14-d incubations in induced cultures while very low activity was observed after an 11-d incubation. SDS-PAGE did not reveal new laccase isoforms when $p$-octylphenol was added to the culture medium: only one isoform was produced $\left(R_{f}=0.47\right)$ whatever the experimental conditions (Fig. 1b). However, on lane b, with induced pre-cultures, the laccase band is strongly stained, showing higher activity under these culture conditions and for the same quantity of proteins in the samples loaded into the gel. Thus, this result suggests that, in our study, the production of the constitutive laccase isoform was enhanced, leading to higher $p$-octylphenol transformation yields. Tanaka et al. (2003) have found that laccase from Trametes sp. and Pycnoporus coccineus decrease the amount of $p$-nonylphenol, $p$-octylphenol and bisphenol A adsorbed on sea sand and the products of oxidation of $p$-nonylphenol are polymers. Sakuyama et al. (2003) have also observed polymers from the oxidation of alkylphenols with Horseraddish peroxidise.

Here, whatever the experimental conditions used, no products of transformation were observed in the extract from cultures. In order to identify the oxidation products, we also tested the transformation of these compounds using the purified isoform of laccase with and without mediators. In these experiments, acetone was used as a solvent for alkylphenols since a previous study has shown that a concentration of $10 \%$ of acetone alters weakly $M$. quercophilus laccase activity (Farnet et al., 2008). After laccase purification from $M$. quercophilus cultures on MEL one band on SDSPAGE (data not shown) was obtained with a molecular weight of $60 \mathrm{KDa}$ as described previously (Farnet et al., 2008). Without ABTS, alkylphenol oxidation by laccase was weak: the percentages of transformation were $37 \pm 2 \%$ and $20.0 \pm 1.5 \%$ for both $p$-t-octylphenol and $p$-nonylphenol and for $p$-octylphenol respectively. When ABTS was added to the reaction mixture, oxidation yields were $92 \pm 1 \%, 67 \pm 2 \%$ and $47.0 \pm 1.5 \%$ for $p$ - $t$-octylphenol, $p$-nonylphenol and $p$-octylphenol respectively. Thus, the use of mediators leading to chemical oxidation strongly increases the yields of the reaction. Cabana et al. (2007) tested the oxidation of $p$-nonylphenol and bisphenol A with laccases from Coriolopsis polyzona. They identified oligomers as products of oxidation with both the endocrine disrupting chemicals tested. Here, MS analysis of $p$-octylphenol products of oxidation (Fig. 3a) indeed show a compound of $\mathrm{m} / \mathrm{z} 411$ which can be assigned to dimers of $p$-octylphenol $\left(\mathrm{C}_{28} \mathrm{H}_{43} \mathrm{O}_{2}\right)$. This compound is indeed ionised in two fragments with $\mathrm{m} / \mathrm{z} 299$ and 187: the loss of two fragments of $m / z 112(411-112=299$ and $299-112=187$ ) may be explained by the loss of ethylene and 1-hexene from the octyl chain from $p$-octylphenol. This mechanism can be extrapolated for both dimers of $p$-octylphenol ( $C-C$ and $\mathrm{C}-\mathrm{O}$ dimers). This result can be of major importance since steric hindrance of the dimers obtained may limit the biological effects of these molecules. Cabana et al. (2007) have demonstrated that the estrogenic effect of nonylphenol and bisphenol A dramatically decreases after oxidation with laccases. Tamagawa et al. (2007) have also observed this result with the oxidised products of $p$-t-octylphenol after laccase and Mn-peroxydase oxidation. Thus, though laccase oxidation does not lead to the degradation of such compounds, estrogenic effects of alkylphenols on organisms may decrease because of their structure modification via polymerisation. 


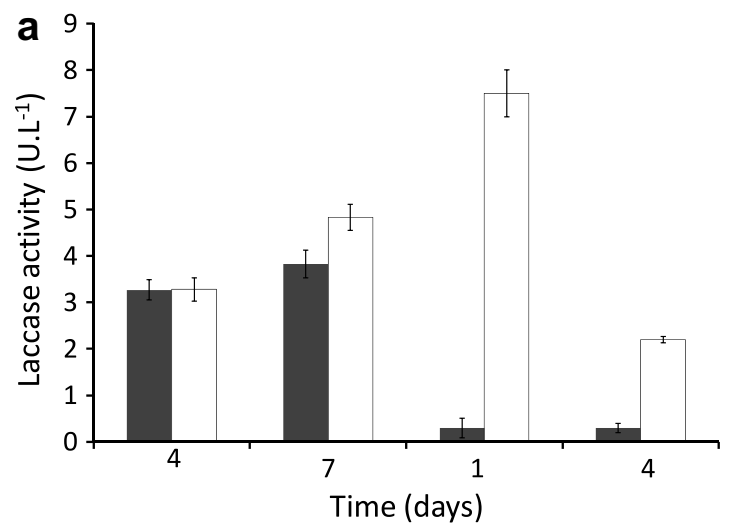

b

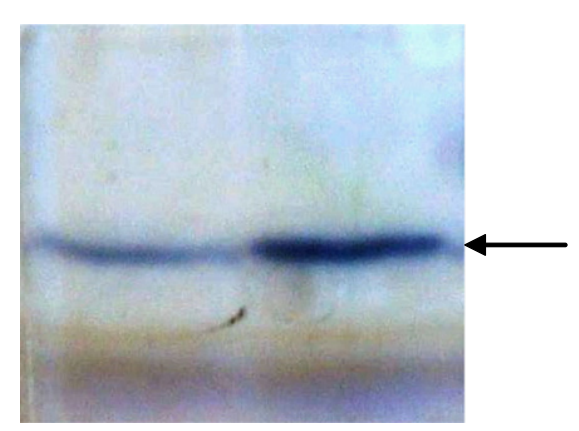

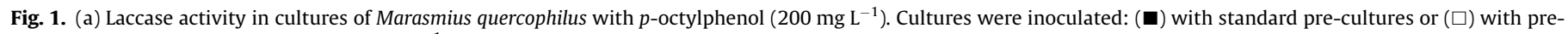

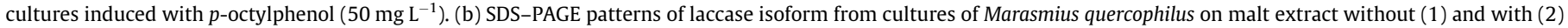
$p$-octylphenol. The arrow indicates the laccase isoform stained with $p$-phenylenediamine.

We also tested alkylphenol oxidation using ABTS as a mediator of laccase activity. This mediator was chosen since previous studies (Pickard et al., 1999; Baiocco et al., 2003; Saito et al., 2004) have shown that ABTS is more efficient than HBT (hydroxybenzotriazole) most probably because of the high redox potential of this molecule. Whatever the alkylphenol tested, the reaction mixture became purple and the chromatogram from HPLC revealed a compound absorbing at $550 \mathrm{~nm}$ (Fig. 2). HPLC-MS-MS was used to identify this compound which has a mass of $476 \mathrm{~m} / \mathrm{z}$ $\left(\mathrm{C}_{23} \mathrm{H}_{30} \mathrm{O}_{4} \mathrm{~N}_{3} \mathrm{~S}_{2}\right)$. The mass spectrum of this fragment contained only one fragment of $244 \mathrm{~m} / z$. Äkerström et al. (2007) have studied the oxidation of tyrosin with ABTS $^{+}$and found a similar purple compound $(451 \mathrm{~m} / \mathrm{z})$. They show that the mass spectrum of ABTS ${ }^{+}$ contains three fragments of 244,259 and $272 \mathrm{~m} / z$ and suggest that the purple compound combines both the fragment from ABTS $^{+}$ $(244 \mathrm{~m} / z)$ and tyrosine. This result suggests that, in our study, $\mathrm{ABTS}^{+}$reacts with alkylphenols and that this reaction leads to a purple product. The structure of the fragment of $244 \mathrm{~m} / \mathrm{z}$ described by Äkerström et al. (2007) is presented in Fig. 3b and indicates the presence of a $\pi$-conjugated system which explains the purple colour of the compound. Fig. 3b also suggests the probable structure of the purple compound $(476 \mathrm{~m} / \mathrm{z}$ ) produced from the reaction between $\mathrm{ABTS}^{+}$and $p$-octylphenol. Thus, this study shows that $\mathrm{ABTS}^{+}$ interacts with the substrate which has to be oxidised and this reaction produce another molecule. This result should be taken into account when ABTS is used as a mediator since it leads to byproducts and affects oxidation yields.

Previous studies have demonstrated that ABTS cannot really be considered as a relevant substrate for laccase activities since the oxidised form, $\mathrm{ABTS}^{+}$, is highly reactive and used as a mediator of laccase oxidation (Terrón et al., 2004; Farnet et al., 2009). Thus, abiotic reactions may occur during enzyme measurement, leading to a misinterpretation of the results. The present study confirms that, in complex environments such as soils or litters where many

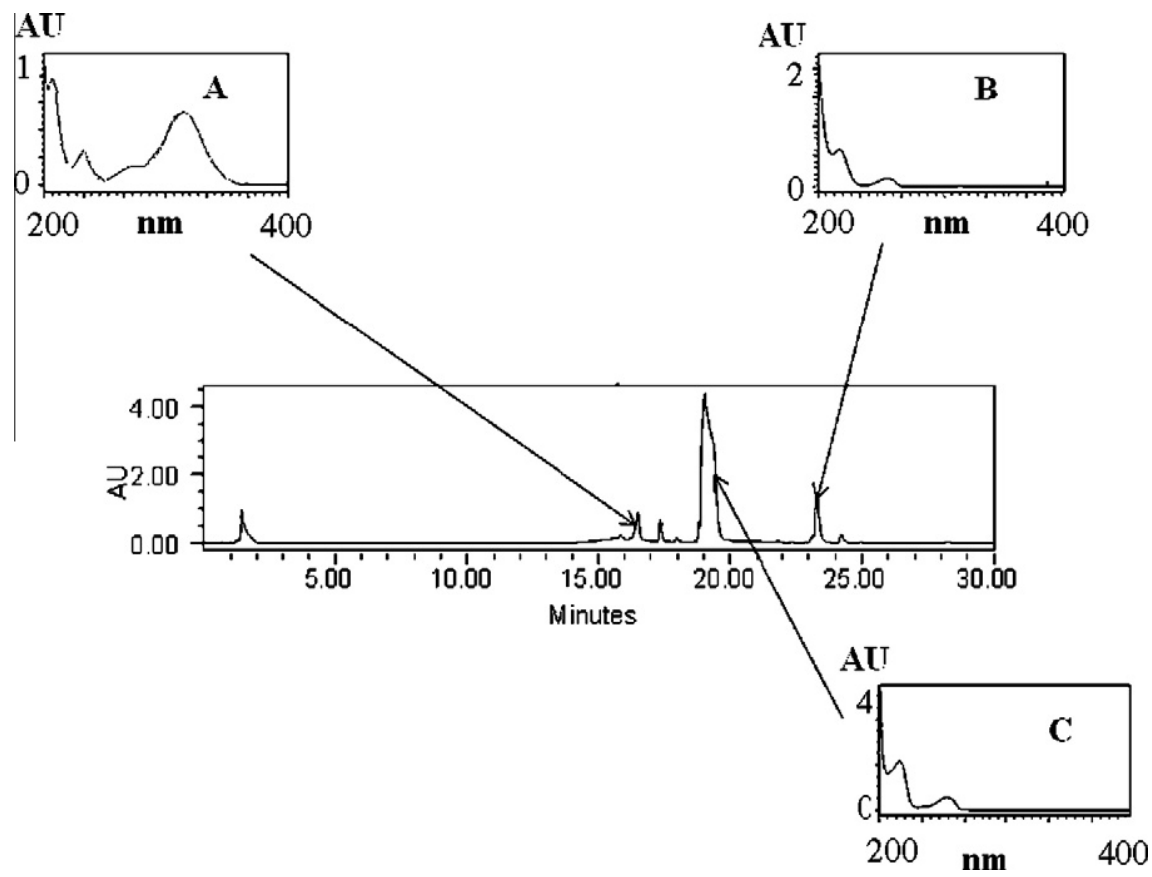

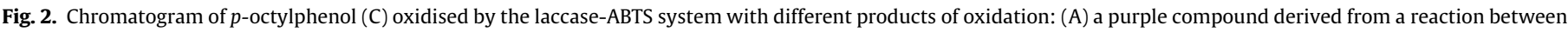
$\mathrm{ABTS}^{+}$and $p$-octylphenol and (B) dimers. 

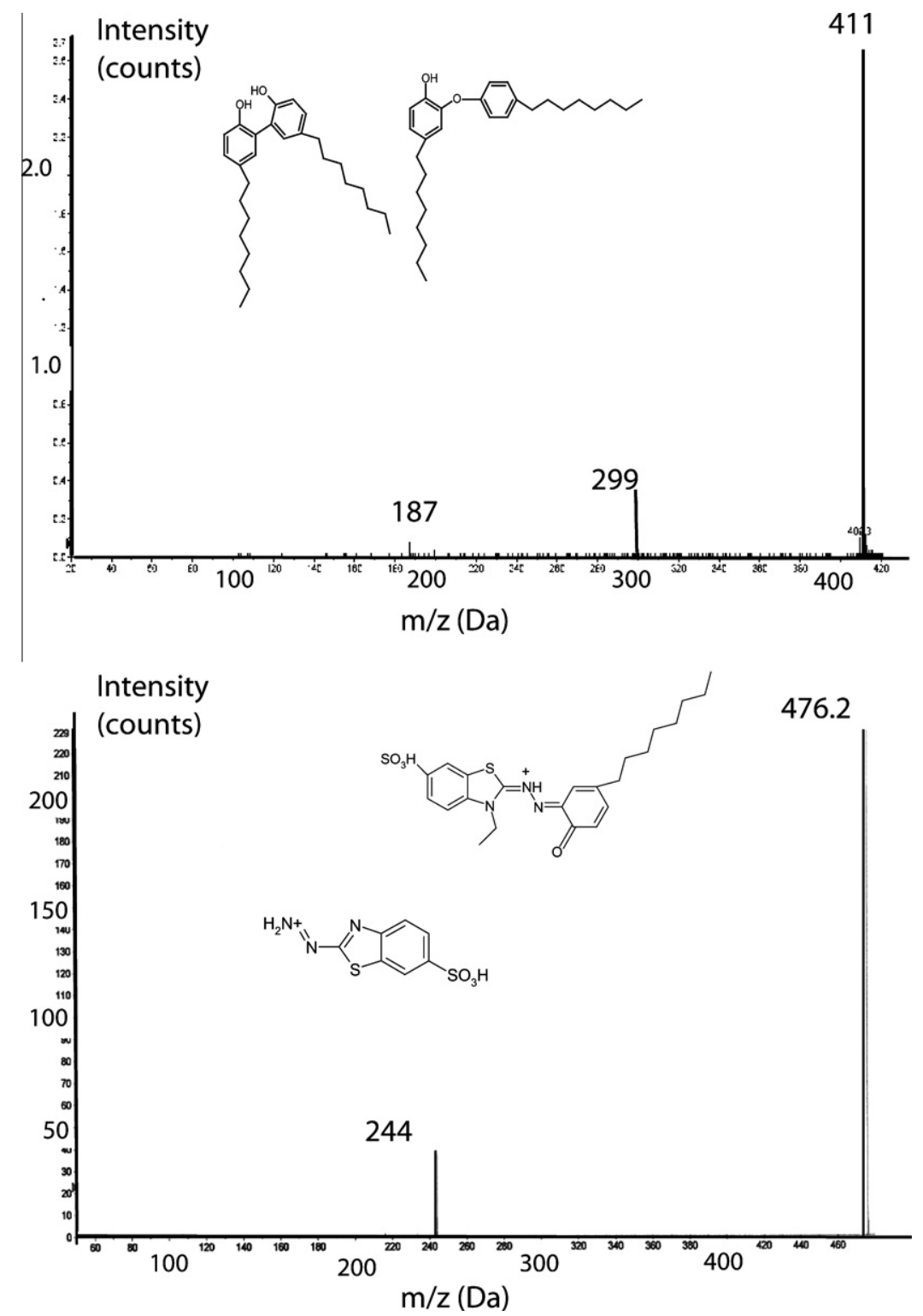

Fig. 3. MS spectrum of: (a) dimers ( $m / z$ 411) from $p$-octylphenol and of (b) a purple compound obtained from the reaction between ABTS ${ }^{+}$and $p$-octylphenol.

molecules can interact with the enzyme substrate or the product of oxidation, laccase activities and those of other phenoloxidases should not be measured with ABTS.

\section{Acknowledgments}

We would like to thank Mrs. Marjorie Sweetko for her very helpful assistance in English language. This work was financially supported by Naturatech (France).

\section{References}

Äkerström, B., Maghzal, G.J., Winterbourn, C.C., Kettle, A.J., 2007. The lipocalin a1microglobulin has radical scavenging activity. J. Biol. Chem. 282, 31493-31503.

Baiocco, P., Barreca, A.M., Fabbrini, M., Galli, C., Gentili, P., 2003. Promoting laccase activity towards non-phenolic substrates: a mechanistic investigation with some laccase-mediator systems. Org. Biomol. Chem. 1, 191-197.

Cabana, H., Jones, J.P., Agathos, S.N., 2007. Preparation and characterization of crosslinked laccase aggregates and their application to the elimination of endocrine disrupting chemicals. J. Biotechnol. 132, 23-31.

Chowen, T.R., Nagler, J.J., 2004. Temporal and spatial occurence of female Chinook salmon carrying a male-specific genetic marker in the Columbia River watershed. Environ. Biol. Fish. 69, 427-432.
Farnet, A.M., Criquet, S., Cigna, M., Gil, G., Ferre, E., 2004. Purification of a laccase from Marasmius quercophilus induced with ferulic acid reactivity towards natural and xenobiotic aromatic compounds. Enzyme Microbiol. Technol. 34, 549-554.

Farnet, A.M., Gil, G., Ferre, E., 2008. Effects of pollutants on laccase activities of Marasmius quercophilus, a white-rot fungus isolated from a Mediterranean schlerophyllous litter. Chemosphere 70, 895-900.

Farnet, A.M., Gil, G., Ruaudel, F., Chevremont, A.C., Ferre, E., 2009. Polycyclic aromatic hydrocarbon transformation with laccases of a white-rot fungus isolated from a Mediterranean schlerophyllous litter. Geoderma 149, 247-271.

Farnet, A.M. Tagger, S. Le Petit, J. 1999. Effects of copper and aromatic inducers on the laccases of the white-rot fungus Marasmius quercophilus. CRAS Life Sci. 322, 499-503.

Ghosh, J.P., Taylor, K.E., Bewtra, J.K., Biswas, N., 2008. Laccase-catalyzed removal of 2, 4-dimethylphenol from synthetic wastewater: effect of polyethylene glycol and dissolved oxygen. Chemosphere 71, 1709-1717.

Harkin, J.M., Larsen, M.J., Obst, J.R., 1974. Use of syringaldazine for detection of laccase in sporophores of wood rotting fungi. Mycologia 66, 469-476.

Laemmli, U.K., 1970. Cleavage of structural proteins during the assembly of the head of bacteriophage T4. Nature 227, 680-685.

Mc Lachland, J.A., 1985. Estrogens in the Environment II. Elsevier, New York.

Nagarnaik, P.M., Mills, M.A., Boulanger, B., 2010. Concentrations and mass loadings of hormones, alkylphenols, and alkylphenol ethoxylates in healthcare facility wastewaters. Chemosphere 78, 1056-1062.

Nagler, J.J., Bouma, J., Thorngaard, G.H. Dauble, D.D. 2001. High incidence of male-specific genetic marker in phenotypic female Chinook salmon from the Columbia River. Environ. Health Persp. 109, 67-69. 
Peck, M., Gibson, R.W., Kortenkamp, A., Hill, E.M., 2004. Sediments ara major sinks of steroidal estrogens in two United Kingdom rivers. Environ. Toxicol. Chem. 23, 945-952.

Pickard, M.A., Roman, R., Tinoco, R., Vazquez-Duhalt, R., 1999. Polycyclic aromatic hydrocarbon metabolism by white-rot fungi and oxidation by Coriolopsis gallica UAMH 8260 laccase. Appl. Environ. Microbiol. 65, 3805-3809.

Sakuyama, H., Endo, Y., Fujimoto, K., Hatana, Y., 2003. Oxidative degradation of alkylphenols by horseradish peroxidase. J. Biosci. Bioeng. 96, 227-231.

Saito, T., Kato, K., Yokogawa, Y., Nishida, M., Yamashita, N., 2004. Detoxification of bisphenol $\mathrm{A}$ and nonylphenol by purified extracellular laccase from a fungus isolated from soil. J. Biosci. Bioeng. 98, 64-66.

Schiliro, T. Pignata, C., Rovere, R., Fea, E., Gilli, G., 2003. The endocrine disrupting activity of surface waters and of wastewater treatment plant effluents in relation to chlorination. Chemosphere $75,335-340$.

Svenson, A., Allard, A.S., Ek, M., 2003. Removal of estrogenicity in Swedish municipa sewage treatment plant. Water Res. 37, 4433-4443.

Tamagawa, Y., Hirai, H., Kawai, S., Nishida, T., 2007. Removal of estrogenic activity of 4-tert-octylphenol by ligninolytic enzymes from white rot fungi. Environ. Toxicol. 22, 281-286.

Tanaka, T., Nose, M., Endo, A., Fujii, T., Taniguchi, M., 2003. Treatment of nonylphenol with laccase in a rotating reactor. J. Biosci. Bioeng 96, 541-546.
Terrón, M.C., López-Fernández, M., Carbajo, J.M., Junca, H., Téllez, A., Yagüe, S., Arana-Cuenca, A., González, T., González, A.E., 2004. Tannic acid interferes with the commonly used laccase-detection assay based on ABTS as the substrate. Biochimie 86, 519-522.

Tollefsen, K-E. Eikvar, S, Finne, E.F, Fogelberg, O, Gregersen, IK, 2008 Estrogenicity of alkylphenols and alkylated non-phenolics in a rainbow trout (Oncorhynchus mykiss) primary hepatocyte culture. Ecotox. Environ. Safe. 71, 370-383.

Torres-Duarte, C., Roman, R., Tinoco, R., Vazquez-Duhalt, R., 2009. Halogenated pesticide transformation by a laccase-mediator system. Chemosphere 77, 687692.

Uhnakova, B., Petrickova, A., Biedermann, A.D., Homolka, L., Vejvoda, V., Bednar, P., Papouskova, B., Sulc, M., Martinkova, L., 2009. Biodegradation of brominated aromatics by cultures and laccase of Trametes versicolor. Chemosphere 76, 826832.

Velazquez-Cedeno, M., Farnet, A.M., Billette, C., Mata, G., Savoie, J.-M., 2007. Interspecific interactions with Trichoderma longibrachiatum induce Pleurotus ostreatus defence reactions based on the production of laccase isozymes. Biotechnol. Lett. 29, 1583-1590. 